Goldschmidt 2021 Abstract

https://doi.org/10.7185/gold2021.6246

\section{REE GEOCHEMISTRY AND EVALUATION OF EFFECTIVENESS OF THE PASSIVE REMEDIATION SYSTEM AT LOUSAL MINE, PORTUGAL}

\author{
CYNTHIA OBREGÓN ${ }^{1}$, MARIA ISABEL PRUDÊNCIO ${ }^{1,2}$, \\ ROSA MARQUES $^{1,2}$, JOÃO CARLOS WAERENBORGH ${ }^{1,2}$, \\ BRUNO J. C. VIEIRA ${ }^{1}$, CATARINA DIAMANTINO ${ }^{3}$ AND \\ EDGAR CARVALHO ${ }^{3}$ \\ ${ }^{1}$ Centro de Ciências e Tecnologias Nucleares (C2TN), Instituto \\ Superior Técnico, Universidade de Lisboa \\ ${ }^{2}$ Departamento de Engenharia e Ciências Nucleares (DECN), \\ Instituto Superior Técnico, Universidade de Lisboa \\ ${ }^{3}$ EDM - Empresa de Desenvolvimento Mineiro \\ Presenting Author: cynthia.castro@ctn.tecnico.ulisboa.pt
}

The remediation process on the Polymetallic Massive Sulphide old mining area of Lousal, affected by Acid Mine Drainage (AMD), currently consists of 17 pools in a wetland system, divided into two different groups, one group for aeration and limestone, and a second one with an aerobic environment (Figure 1).

Previous researches have focused on the chemical composition of AMD in Lousal before the installment of the passive treatment system that started in $2010 / 2011$ by Empresa de Desenvolvimento Mineiro (EDM). This study aims to evaluate the effectiveness and the distribution of REE in course of the remediation system.

Rare Earth Elements (REE) concentrations in water samples were determined using inductively coupled plasma mass spectrometry. The bulk composition of soil and sediments samples were determined by Instrumental Neutron Activation Analysis and ICP-MS. Iron and other elements relevant for the understanding of REE behavior were also studied. The major mineral phases were identified by X-ray diffraction. Alongside, the $\mathrm{Fe}$ speciation was determined using Mössbauer Spectroscopy. The outcome of these measurements allows the understanding of the spatial variations in all the sub-systems involved in the stream water, acidic drainage and water within the passive treatment system.

The field parameters measured on-site showed no significant variations of $\mathrm{pH}$ and electrical conductivity among the remediation system. However, the element concentration obtained from the water shows some changes in the metal concentration, especially Fe. The water has higher concentrations of LREE in comparison to HREE in all the different sub-systems, with an increase of the concentration of HREE passing through the wetland system. Mössbauer spectra display that the Lousal Mine samples measured have similar Fe oxidation degrees, i.e. similar $\mathrm{Fe}^{3+} / \mathrm{Fe}^{2+}$ ratios. Sediments at the end and before the passive remediation system show a similar Fe oxidation degree. The main difference is the lower Fe contents and a significantly higher fraction of $\mathrm{Fe}$ on nanosized oxides at the end of the passive remediation system.

\section{Acknowledgements}

PANORAMA - 'EuroPean trAining NetwOrk on Rare eArth elements environMental trAnsfer: from rock to human' (EU Project 857989, H2020-MSCA-ITN).

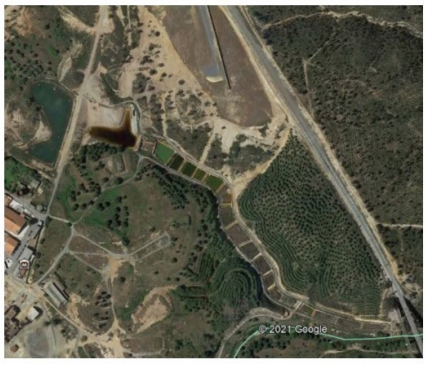

